\title{
Cycling at the interface between neurodevelopment and neurodegeneration
}

\author{
MD Nguyen ${ }^{1,3}$, WE Mushynski ${ }^{2}$ and J-P Julien ${ }^{\star, 1}$ \\ ${ }^{1}$ Centre for Research in Neurosciences, Research Institute of the McGill \\ University Health Centre, Montreal General Hospital, 1650 Cedar Avenue, \\ Montréal, Québec, H3G 1A4, Canada \\ 2 Department of Biochemistry, McGill University, McIntyre Medical Sciences \\ Building, 3655 Promenade Sir William Osler, Montréal, Québec, H3G 1Y6, \\ Canada \\ ${ }^{3}$ Current address: Harvard Medical School, Department of Pathology, \\ 200 Longwood Avenue, Boston, MA 02115 \\ * Corresponding author: J-P Julien. Tel: 934-1934 ext 44203; Fax: 514-934- \\ 8265; E-mail: mdju@musica.mcgill.ca. For correspondence use the Fedex no: \\ 1316-8394-4.
}

Received 17.5.02; revised 23.7.02; accepted 23.7.02

Edited by G Melino

\begin{abstract}
The discovery of cell cycle regulators has directed cell research into uncharted territory. In dividing cells, cell cycleassociated protein kinases, which are referred to as cyclindependent-kinases (Cdks), regulate proliferation, differentiation, senescence and apoptosis. In contrast, all Cdks in postmitotic neurons, with the notable exception of Cdk5, are silenced. Surprisingly, misregulation of Cdks occurs in neurons in a wide diversity of neurological disorders, including Alzheimer's disease, Parkinson's disease and amyotrophic lateral sclerosis. Ectopic expression of these proteins in neurons potently induces cell death with hallmarks of apoptosis. Deregulation of the unique, cell cycle-unrelated Cdk5 by its truncated co-activator, p25 and p29, contributes to neurodegeneration by altering the phosphorylation state of non-membrane-associated proteins and possibly through the induction of cell cycle proteins. On the other hand, cycling Cdks such as Cdk2, Cdk4 and Cdk6, initiate death pathways by derepressing E2F-1/Rb-dependent transcription at the neuronal G1/S checkpoint. Thus, Cdk5 and cycling Cdks may have little in common in the healthy CNS, but they likely conspire in leading neurons to their demise.

Cell Death and Differentiation (2002) 9, 1294 - 1306. doi:10.1038/ sj.cdd. 4401108

Keywords: cyclin-dependent-kinases; neurodevelopment; neurodegeneration; alzheimer; amyotrophic lateral sclerosis; cell cycle; cytoskeleton
\end{abstract}

Abbreviations: Cdks, cyclin-dependent-kinases; CKIs, CDKInhibitory subunits; AD, Alzheimer's disease

\section{Introduction}

Members of the Cyclin-dependent protein kinase (Cdk) family are small, serine/threonine kinases $(30-35 \mathrm{kDa})$, whose nine members share greater than $40 \%$ identity. With the exception of Cdk3 and Cdk5, they are activated by a cyclin regulatory subunit ${ }^{1-3}$ (see Figure $2 \mathrm{~A}$ ). The Cdks are numbered in order of their discovery, starting with Cdk1 (p34cdc2) and extending at present to Cdk9. The 'Cdk' designation does not imply that the biological functions of Cdks are limited to mitosis. The classical Cdks, excepting Cdk5 and Cdk9, are also involved in regulating cellular processes such as differentiation, senescence, and apoptosis through modification of gene transcription. ${ }^{2}$ In proliferating cells, misregulation of Cdks is associated with tumor formation, whereas their disappearance/inhibition in neuronal precursors coincides with terminal differentiation. ${ }^{4}$

Cdk5 is a unique member of the Cdk family. Although its cloning was based on sequence homology to the cell cycle kinase, Cdk1, Cdk5 does not play a critical role in cell cycle progression. ${ }^{1}$ It is not activated by a cyclin, although it can bind one such protein. ${ }^{5}$ The association of Cdk5 with one of its neuron-specific co-activators, p35 or p39, is required in processes such as neurite outgrowth, axonal migration, cortical lamination, control of cell adhesion, axonal transport, synaptic activity, neuronal adaptive changes and motor functions. ${ }^{1}$ The prominent role of Cdk5 in the CNS stems from its unique co-activators and the broad spectrum of Cdk5-interacting molecules and substrates demonstrated by genetic studies in the mouse and fruitfly. Emerging evidence also points to a leading role for Cdk5 as well as other Cdks in neuronal apoptosis and degeneration.

This review will focus on the basic mechanisms regulating the divergent roles of Cdks in the CNS and their common involvement in neuronal apoptosis and neurodegeneration.

\section{Divergent regulation of Cdk5 and cell cycle Cdk activities}

Cdk activity is regulated by three distinct overlapping mechanisms, the critical step being their association with a co-activator. Phosphorylation/dephosphorylation events prime Cdks for activation by regulatory subunits while a family of Cdk-inhibitory subunits (CKIs) bind to and inactivate the Cdk-cyclin complex. ${ }^{1,6}$ Thus, formation of a Cdk1/cyclin B complex late in S-phase triggers phosphorylation of Cdk1 on Thr 14 and Tyr 15 by the dual-specificity kinases, Wee 1 and Myt1, thereby inhibiting its activity. ${ }^{1,7-9}$ In contrast, phosphorylation of Thr 161 in the T-loop of Cdk1 by the Cdk-activated kinase, CAK (CDK7-cyclin $\mathrm{H}$ ) dramatically increases kinase activity. ${ }^{1,9}$ These three sites are phosphorylated throughout the G2-phase. Dephosphorylation of Thr 14 and Tyr 15 by the 
dual-specificity phosphatase, Cdc25, results in the activation of Cdk1/cyclin B coinciding with the onset of mitosis. ${ }^{10,11}$ Finally, additional regulation by Cdk-inhibitory subunits (CKIs) such as p21 and p27 (in the case of Cdk2) inhibit activation of the $\mathrm{Cdk} /$ cyclin complex. $^{6}$

The regulation of Cdk5 differs markedly from that of the cell cycle Cdks, despite its high level of sequence homology with the other family members. Thus, the Thr14 and Tyr15 sites in Cdk5 are not phosphorylated by Wee1 in vitro, and cAbl catalyzes the stimulatory phosphorylation of Tyr15 in Cdk5. ${ }^{12}$ Surprisingly, phosphorylation of Thr14 in Cdk5, Cdk1 and Cdk2 by a kinase from calf thymus gland inactivates the three enzymes. ${ }^{13}$ The Ser159 residue in Cdk5 occupies a position equivalent to the Thr161 and Thr160 phosphorylation sites in the conserved T-loop of Cdk1 and Cdk2, respectively, and in vitro studies have suggested that Cdk5 undergoes stimulatory phosphorylation at this site by an unknown kinase, possibly casein kinase I. 6,14 However, structural analysis of a complex between Cdk5 and p25, a truncated version of the p35 co-activator of Cdk5, indicated that phosphorylation of Ser159 would disrupt the association of Cdk5 with its co-activator. ${ }^{15}$ In addition to its distinct phosphorylation-dependent regulation, Cdk5 is not regulated by CKI because of its association with p35. ${ }^{16}$ However, a p35-binding protein that specifically inhibits the activation of Cdk5 has recently been reported. ${ }^{17}$

\section{Phosphorylation sequence motif specificity of Cdks}

Cdk5 is a proline-directed kinase which preferentially phosphorylates the consensus sequence $(\mathrm{S} / \mathrm{T}) \mathrm{PX}(\mathrm{K} / \mathrm{H} / \mathrm{R})$, where $\mathrm{S} / \mathrm{T}$ is a serine or threonine residue, $\mathrm{P}$ is the proline residue at position $+1, \mathrm{X}$ is any amino acid and $\mathrm{K}, \mathrm{H}$ or $\mathrm{R}$ is a lysine, histidine or arginine residue, respectively., ${ }^{1,15}$ Cdk5 shows a marked preference for a basic residue at position +3 . $^{18}$ The human neurofilament heavy chain (NF-H), a major cytoskeletal protein found in mature nerve cells, contains 35 KSPXK repeats and is therefore a much better $\mathrm{Cdk} 5$ substrate than the mouse or rat homologs which contain one-third as many such motifs. ${ }^{19}$ The only Cdk family members showing phosphorylation sequence motif specificity identical to that exhibited by Cdk5 are Cdk1, Cdk2. Others members of the family preferentially phosphorylate the KSPXX motif.

Specificity in substrates recognition for mitotic Cdks is dictated by their association with cyclins subunits and by the cyclin-binding motif ZRXL and the LXCXE motif. ${ }^{6,20}$

While the ZRXL motif is found in cell cycle-associated proteins such as Cip/Kip CKI family, E2F-1 and pRb-related proteins p107, p130, the LXCXE motif is part of the cyclin protein. $6,20-22$ This motif is also found in pRb-associated proteins such as transcription factors and is likely to serve a targeting function. Therefore, substrates for mitotic Cdks are mainly cell cycle and transcription-related proteins. Conversely, Cdk5 specificity for substrate recognition is dictated by p35, p39 and by truncated forms of these coactivators (see below).

\section{Cell cycle Cdks in the CNS and neurodegeneration}

The levels of Cdks, cyclins and CKI in dividing cells are tightly controlled to allow smooth progression through the cell cycle. Conversely, the expression of cell cycle Cdks in the adult CNS is negligible since they do not play a significant role in mature neurons. As neurons differentiate, Cdk1 and Cdk2 are downregulated while Cdk5, p35 and p39 expression begins $^{4,23,24}$ (see Figure 1). Some studies report the presence of

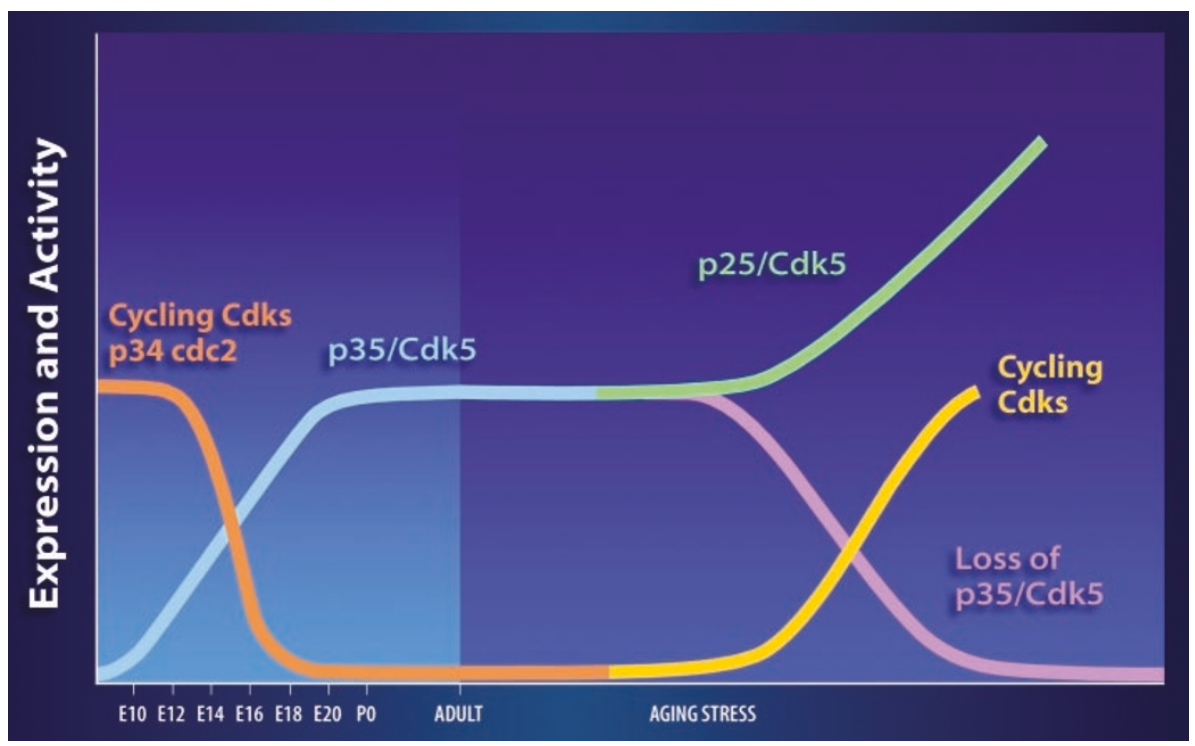

Figure 1 Activity of cycling Cdks and Cdk5 during neurodevelopment and neurodegeneration. There is an inverse relation between the activity and expression of cycling Cdks, such as p34cdc2 (Cdk1), and Cdk5 during neurodevelopment. The activity and expression of p34cdc2 decreases progressively as those of Cdk5 increase. At the adult stage, Cdk5 is the main Cdk to be found active in the CNS through association with its neuron-specific co-activators p35 and p39. Aging, stress and genetic factors induce the progressive cleavage of p35 into p25, resulting in an increased Cdk5 activity. In parallel, activity and expression of cycling Cdks also increase progressively. The conversion of p35 into p25 results in loss of the p35/Cdk5 complex and activity 
the CKIs, p19ink4d and p27kip, in mature neurons of the neocortex and hippocampus, suggesting a dormant cell cycle that potentially can be activated under appropriate circumstances. $^{25}$ Indeed, the expression of CKI in neurons correlates with their withdrawal from the cell cycle. ${ }^{24,26} \mathrm{~A}$ recent study reports a novel cyclin that may play an important role in dopamine signaling but, to date, no kinase has been found to be associated with this cyclin. ${ }^{27}$

Other Cdk1-related kinases, named according to sequence homology in the PSTAIRE motif (residues 45-51) found in Cdk1, Cdk2 and Cdk3, have also been cloned. These kinases are not considered to be members of the Cdk family since their cyclin partners remain to be identified. One of these kinases is PFTAIRE, which is found in the soma, nucleus and axon of some terminally differentiated neurons whose functions remain undefined. ${ }^{28}$ Although there is some evidence that Cdk1-related kinases other than Cdk5 play a role in the CNS, it is unlikely that cycling Cdks are involved in the normal biology of mature nerve cells.

In contrast, there is a growing evidence for the involvement of cell cycle Cdks in neurodegenerative disorders and neuronal apoptosis. ${ }^{29-31}$ Induction of cycling Cdks occurs in vivo in mature adult neurons during focal stroke and kainate-induced excitotoxicity. ${ }^{32,33}$ It is also seen in primary neuronal cultures deprived of trophic factors or treated with DNA damaging agents, 3-nitroproprionic acid or $\beta$-amyloid peptide, the latter being a major toxic component in Alzheimer's disease (AD). ${ }^{31,34}$ The induction of proliferating Cdks in neurons is associated with their dedifferentiation and triggers neuronal death that can be rescued by the use of Cdk inhibitors or by expression of dominant negative forms of the kinases. ${ }^{29,31}$ Mouse models of neurological disorders also exhibit abnormal expression of cell cycle proteins in degenerating neurons. ${ }^{30,31}$

In proliferating cells, the resting phase (G0) of the cell cycle is followed by the first gap phase (G1) during which cells prepare for DNA replication in the ensuing S-phase. There follows a second gap phase (G2) which precedes the mitosis (M-phase) (see Figure 2A). Phosphorylation of the retinoblastoma protein $(\mathrm{Rb})$ by $\mathrm{Cdk} 4, \mathrm{Cdk} 6$ and Cdk2 leads to initiation of and progression through the cell cycle. ${ }^{2}$ In contrast, phosphorylation of $\mathrm{Rb}$ by these Cdks in neurons induces apoptosis through the dissociation of $\mathrm{Rb}$ from the $\mathrm{Rb} / \mathrm{E} 2 \mathrm{~F}-1$ transcription repressive complex and subsequent E2F1-dependent expression of apoptotic proteins (see Figure 2B). ${ }^{29}$ This neurotoxic cell cycle event likely involves induction of the transcription factors B- and C-myb. ${ }^{35}$ Similar cell cycle protein expression patterns are seen in neurons in simian and human immunodefficiency virus encephalitis and the changes correlate with increased levels of activated macrophages. ${ }^{36}$ This suggests a close relationship between deregulation of cell cycle Cdks and inflammation during neurodegeneration (for a review on the role of inflammation in neurodegeneration, see ref. ${ }^{37}$ ).

As revealed in primary cortical neurons treated with $\beta$ amyloid peptide, $\mathrm{Rb}$ phosphorylation by $\mathrm{Cdk} 4 / 6$ can cause an imbalance in the ratio between pro-apoptotic (Bax) and anti-apoptotic (Bcl-2) members of $\mathrm{Bcl}-2$ family, resulting in caspase-3 activation and apoptosis. ${ }^{34}$
Alterations in the expression and cellular distribution of cell cycle proteins have been observed in post-mortem neurons from patients with $A D$, Down Syndrome, Pick's disease and Parkinson-ALS of Guam. ${ }^{30,31}$ For example, levels of the Cdk-activating tyrosine phosphatase cdc25 and the Cdk-activating kinase $\mathrm{Cdk} 7 /$ cyclin $\mathrm{H}$ (see above) are abnormally elevated in the brain of $A D$ patients. ${ }^{38-40}$ Furthermore, aberrant expression of the M-phase regulator Cdc2/Cyclin B1 also occurs in degenerating neurons in AD. ${ }^{30,41}$ Direct evidence for DNA replication in AD was provided by a study showing that four separate loci on three different chromosomes were fully or partially replicated in hippocampal pyramidal and basal forebrain neurons. ${ }^{42}$ Further evidence that activation of the cell cycle initiates neuronal death derives from the finding that unaffected regions of $A D$ brain or hippocampus from nondemented age-matched controls exhibit no such anomalies. ${ }^{42}$ Available information therefore indicates that disturbances in the biology of cell cycle regulators in neurons are likely to contribute to neurodegeneration.

\section{Cdk5 in neurodevelopment}

Cdk5 is currently the only functional Cdk found in healthy mature neurons of the CNS where it orchestrates multiple processes including membrane trafficking, transport and neurotransmission. In the developing CNS, Cdk5 plays a crucial role in axonal migration by modulating actin-based motility and cell adhesion. Cdk5 mediates these functions in association with its neuron-specific co-activators.

\section{p35 and p39 are neuron-specific co-activators of Cdk5}

Cyclin D1 binds to Cdk5 but is unable to activate the kinase. ${ }^{5}$ The almost exclusive Cdk5 activity in the forebrain and spinal cord is regulated by two neuron-specific co-activators, p35 and p39. ${ }^{23,43,44}$ These two proteins do not share significant sequence homology with cyclins, which are the prototypical activators of cell cycle Cdks such as Cdk1 and Cdk2. However, crystallographic studies indicate that p25, a calpain cleavage fragment of $\mathrm{p} 35$, can assume a conformation similar to the cyclin-box fold. ${ }^{15}$

Homologs of p35 have been discovered in Xenopus, $C$. elegans and Saccharomyces cerevisiae, indicating that the protein has been conserved during evolution. Screening of a rat hippocampal cDNA library led to the discovery of one mammalian homolog, p39. ${ }^{45}$ p39 shows $57 \%$ sequence identity with p35 and up to $65 \%$ identity with p25, which promotes the sustained activation of Cdk5 (see below). ${ }^{45,46}$ Recently, p29, a truncated form of p39, was also shown to hyperactivate Cdk5, although no in vivo cleavage product of p39 has been demonstrated to date ${ }^{47}$ (see Figure 4). The finding that p35 null mice exhibited residual Cdk5 activity suggested that p39 was a co-activator of Cdk5 in vivo. ${ }^{44,48,49}$ The absence of residual Cdk5 activity in p35/p39 double knockout mice indicates that p35 and p39 are the major, if not the only, Cdk5 activators in the CNS. ${ }^{44,48,49}$

While Cdk5 is present in the CNS as well as in PNS structures such as dorsal root ganglia, in situ hybridization 

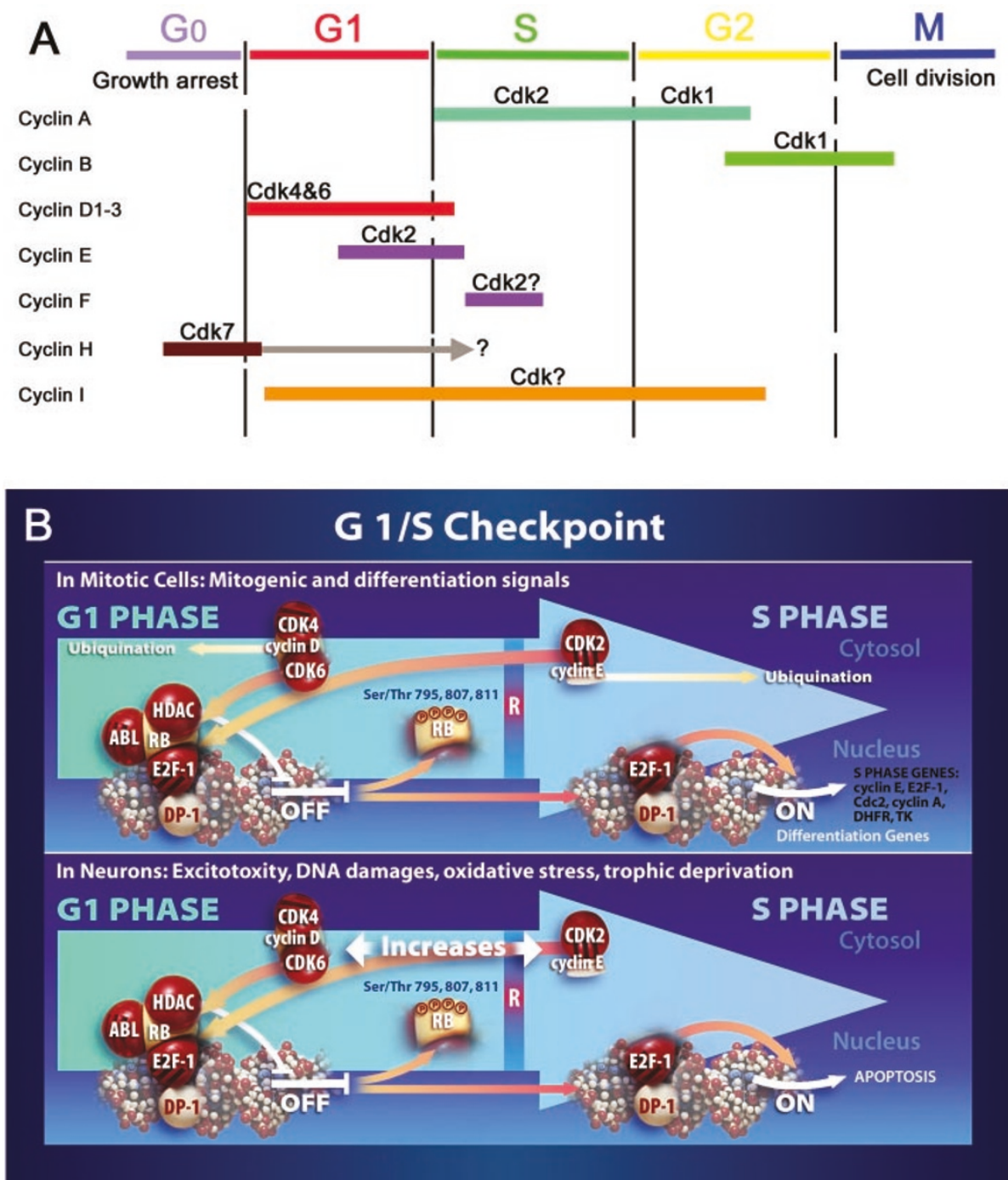

Figure 2 Cycling Cdks in proliferating cells and neuronal death. (A) In proliferating cells, cell cycle Cdks and their associated cyclins are tightly regulated to account for the progression through the cell cycle. Cdk4 and Cdk6 in association with cyclin D1-3 are the main kinases that are involved in the early control of the G1/S checkpoint while Cdk2/cyclin E complex is involved in late stage of the G1/S checkpoint. In synergy with Cdk1, the Cdk2/cyclin A complex also mediates the S/G2 transition. In addition, Cdk1 in association with cyclin B allows the progression from the G2 phase to M-phase. Cyclin I, together with cyclin G (not shown) defines a novel cyclin family expressed in terminally differentiated tissues including brain, heart and muscle. The expression of cyclin I mRNA does not correlate directly to the cell cycle, suggesting that this cyclin functions independently of the cell cycle control. The kinases that associate with this cyclin remain undefined. It remains unclear whether Cdk7/cyclin H is important after the G0/G1 point. (B) At the G1/S checkpoint, phosphorylation of Rb by Cdk4 and Cdk6 leads to the disruption of the transcription repressive E2F-1/Rb complex, causing the inactivation of Rb and consequently promotes E2F-1-dependent transcription of proteins involved in cell cycle progression and differentiation. In contrast, in postmitotic neurons, cycling Cdks are silenced. However, they are re-expressed when neurons are subjected to various insults (excitotoxicity, DNA damages, oxidative stress, trophic deprivation). The phosphorylation of Rb by cycling Cdks in neurons can induce apoptosis through the dissociation of $\mathrm{Rb}$ from the Rb/E2F-1 transcription repressive complex and the subsequent E2F-1-dependent expression of apoptotic proteins such as $\mathrm{p} 53$ and Bax

indicated a restricted expression of p35 in the developing CNS of mouse embryos as early as E10. ${ }^{23,43,50-52}$ Expression studies of E12 and E15 mouse brains revealed that there is no p35 in proliferating neuronal precursors but that it is expressed in postmitotic neurons of the developing cortex. $^{50}$ Indeed, the early stage of Cdk5 expression in differentiating neurons coincides with the disappearance of cell cycle Cdks. ${ }^{4,23,24,43,50}$ In postnatal and adult rat brain, p35 is relatively abundant in most areas of the forebrain, including the neocortex and hippocampus. ${ }^{23,43,50-52}$ p39 mRNA is found in the developing and adult CNS, including the spinal cord, as well as in the PNS. ${ }^{52}$, Since the highest level of p39 expression in the CNS occurs postnatally, p39/ Cdk5 may mediate functions distinct from those involving p35/Cdk5 during neurodevelopment. Subcellular distribution studies indicate both distinct and overlapping features. ${ }^{54,55}$ Thus, p39 null mice do not display an overt phenotype whereas p35 null mice exhibit a neurological phenotype that cannot be corrected by p39, indicating that p35 can mask the lack of p39. ${ }^{44,48,49}$ The association of p35/Cdk5 and $\mathrm{p} 39 / \mathrm{Cdk} 5$ with the plasma membrane is directed by the myristoyl moiety linked to the $\mathrm{N}$-terminal glycine of p35 and 
p39 $9^{46,47,55}$ and places limitations on the number of potential substrates accessible to Cdk5.

\section{Neurite outgrowth, axonal migration and corticogenesis}

Cellular mechanisms involving Cdk5 are essential for several neurodevelopmental processes. Inhibition of Cdk5 or expression of a dominant negative form of the kinase in cultured cortical and cerebellar neurons prevents neurite outgrowth whereas overexpression of $\mathrm{p35} / \mathrm{Cdk5}$ induces the formation of longer neurites, thereby indicating that Cdk5 is involved in neurite outgrowth., 55 In axonal growth cones, p35/Cdk5 colocalizes with PAK1 and Rac, a member of the Rho family of small GTPase proteins. ${ }^{55}$ Under these circumstances, p35/ Cdk5 phosphorylates PAK1 at threonine 212 in a Racdependent manner and down-regulates its kinase activity. ${ }^{56}$ p35/Cdk5 can also be co-immunoprecipiated with cdc42 and phosphorylated PAK1 from preparations containing Golgi membrane. ${ }^{57}$ Suppression of Cdk5 activity in developing neurons by antisense oligonucleotides or inhibitors abolishes the formation of membrane vesicles from the Golgi apparatus, indicating a role for Cdk5 in membrane trafficking during neurite outgrowth. ${ }^{57}$ Since Rho family GTPases and PAK kinases modulate actin cytoskeleton dynamics and establishment of neuronal polarity, p35/Cdk5 may orchestrate the reorganization of actin in the growth cone and on Golgi membranes during neurite elongation.

Neurite outgrowth in cortical cultures can be enhanced by overexpression of c-Abl and is reduced by treating the cells with c-Abl antisense oligonucleotides. Cdk5 is phosphorylated at Tyr15 by c-Abl and this process is enhanced by Cables ( $\underline{C} d k 5$ and $\underline{A b l}$ enzyme substrate), which links Cdk5 to c-Abl. ${ }^{12}$ This results in the dissociation of Cdk5 from the c-Abl/Cables complex and in stimulation of Cdk5 activity through its association with p35. ${ }^{12}$ Unequivocal in vivo roles for $\mathrm{p} 35 / \mathrm{Cdk} 5$ in neurite outgrowth and axonal migration were demonstrated by analysis of both p35- and Cdk5-null mice.

The mammalian brain is built in an inside-out manner because during migration earlier-differentiating cortical neurons are passed by neurons that differentiate later, giving rise to the typical six-layered structure of the cortex with earlier differentiating neurons occupying deeper cortical layers. ${ }^{1}$ Analysis of p35-null mice by bromodeoxyuridine $(\mathrm{BrDU})$-labeling revealed that the overall cellular pattern in the cortex was inverted due to the inability of the more recently differentiated cohort of cortical neurons to migrate past their predecessors. ${ }^{48,49}$ The resulting loss of stratified cellular organization is evident at E15. In addition, Golgi staining revealed the absence of oriented apical dendrites in pyramidal neurons from p35-null mice, indicating the loss of neuronal polarity. ${ }^{48,49}$ This finding highlights that p35-deficient neurons have uncompleted their differentiation.

A more severe disruption of embryonic cortical layering is observed in mice lacking Cdk5 despite the kinase not being required for migration of neurons into layers $I$ and VI. ${ }^{58,59}$ Cdk5-null mutant mice die in utero after E16.5, with the remainder dying at birth. ${ }^{58}$ Lesions are observed only in the brain and spinal cord and chromatolytic changes such as a ballooned cell soma with eccentric nucleus are seen in motor neurons of these mice ${ }^{58}$ The lethality associated with Cdk5 gene deletion can be completely prevented by restricting overexpression of Cdk5 to neurons with the neuron-specific p35 promoter, indicating that Cdk5 is crucial for survival of developing neurons. ${ }^{60} \mathrm{~A}$ study of Cdk5-deficient chimeric mice revealed that the kinase promotes survival in an autonomous manner. ${ }^{61}$ The differences between Cdk5- and p35-null mice can be explained by assuming that p39 compensates for p35 in the latter case. While p39 knockout mice do not exhibit an overt phenotype, double p35/p39-null mice are identical to Cdk5-null mice. ${ }^{44,48,49,58}$

The cortical phenotypes of Cdk5-, p35- or p35/p39-null mice resemble a severe developmental disorder in humans, caused by a haploinsufficiency of the Lis 1 product and referred to as type 1 lissencephaly. ${ }^{62}$ Lis1-knockout mice are embryonic lethal while heterozygotes display neuronal migration defects, suggesting a dosage-dependent severity. ${ }^{62}$ Lis1 is a WD repeat protein, which acts as a noncatalytic subunit of the platelet-activating factor, acetylhydrolase 1B (PAFAH1B). Lis1 also associates with cytoplasmic dynein and tubulin and regulates microtubule organization in vitro. ${ }^{62,63}$ Nudel, a novel Cdk5 substrate, binds Lis1 and inhibition of Cdk5 in developing neurons causes Nudel to accumulate in neurites and axons. ${ }^{64}$ Cross-talk between the Lis1 and p35/Cdk5 pathways may impact on neuronal migration and axon growth either directly by regulating transport or indirectly through the control of nuclear translocation during migration. Indeed, NudF, a Lis1 homolog in Aspergillus nidulans, was identified as a mutation characterized by defective nuclear migration. ${ }^{62,63}$ The class III pou domain transcription factors, Brn-1 and Brn-2, are reported to control the initiation of radial migration by regulating p35 and p39 expression in migrating cortical neurons. Hence, double Brn-1/Brn-2 gene knockout mice exhibit cortical inversion. ${ }^{65}$ In summary, Cdk5 promotes axonal migration by modulating cytoskeletal dynamics, transport and membrane trafficking.

\section{Corticogenesis is intimately linked to cell adhesion}

The proper migration of neurons during cortical development requires regulated cell adhesion processes. In the developing cerebral cortex, the binding of a secreted protein, Reelin, to lipoprotein receptors (VLDLr, ApoER2) is likely to control homotypic cell adhesion during neuronal migration, thereby allowing neurons/axons to sense and respond to extracellular cues for neuronal positioning in laminated brain regions such as the cerebral cortex, cerebellum and hippocampus. ${ }^{66}$ Genetic and biochemical studies demonstrate that phosphorylation of the tyrosine kinase adaptor, Dab1, in response to Reelin signaling is a critical step in the release from cell adhesion required to allow migration. ${ }^{66}$ Cross-talk between the p35/Cdk5 and Reelin/Dab1 pathways was suggested due to the similarities of Reeler mice (reelin deficient mice) and Scrambler/Yotari mice (Dab1 deficient mice) with p35- and Cdk5-null mice. While p35-null mice exhibit only mild 
abnormalities in the hippocampus and none in the cerebellum, double p35/reelin-null mice and double p35/cdk5-knockout mice show additional defects in neuronal migration involving Purkinje cells in the cerebellum and pyramidal neurons in the hippocampus. ${ }^{67}$ These results indicated that there is a synergism between p35/Cdk5 and Reelin/Dab1 during cortical development. It is interesting to note that p35/Cdk5 can phosphorylate Dab1 in vitro and in vivo, independently of the Reelin signaling. ${ }^{68} \mathrm{p} 35 / \mathrm{Cdk} 5$ is also associated with $\beta$ catenin and controls $\mathrm{N}$-cadherin/ $\beta$-catenin-mediated cell adhesion through phosphorylation of $\beta$-catenin. As revealed by aggregation assays, which provide a measure of $\mathrm{N}$ Cadherin-mediated adhesion, a loss of Cdk5 activity, achieved by deletion of p35 or by use of a Cdk5 inhibitor, causes the formation of larger aggregations of cortical neurons. $^{69}$ The coordinated regulation of cell adhesion and p35/Cdk5-dependent migration is further indicated by the finding that activation of Cdk5 occurs following binding of laminin to the $\alpha_{1} \beta_{1}$-integrin receptor during neurite outgrowth and by studies of p35-null mice showing defects in the fasciculation of several major axon tracts. ${ }^{48,49,70}$ From this perspective, cortical defects triggered by deletion of the p35 gene may not be due exclusively to the inability to promote neuronal migration but may also be caused by a failure to efficiently regulate cell adhesion dynamics.

\section{Cdk5 in the adult CNS: motor functions, plasticity and neurotransmission}

In contrast to cell cycle Cdks, Cdk5 is a major component of mature neurons. The prominent roles played by Cdk5 in synaptic activity and in survival of terminally differentiated neurons involve a widespread panel of substrates. ${ }^{1}$ For instance, DARPP-32 (dopamine and cAMP regulated phosphoprotein), is a Cdk5 substrate that plays a key role in the biology of medium spiny dopaminoceptive GABAergic neurons in the striatum, a nevralgic structure modulating voluntary motor movements and motivational behavior. ${ }^{71,72}$ Cdk5 phosphorylation of Thr 75 transforms DARPP-32 into an inhibitor of Protein Kinase A (PKA) whereas phosphorylation of Thr 34 by PKA, makes it a potent inhibitor of protein phosphatase-1 (PP-1). ${ }^{71,72}$ Furthermore, phosphorylation of protein phosphatase inhibitor-1 (PPI-1) by Cdk5 lowers the efficiency of PPI1phosphorylation by PKA. ${ }^{71,72}$ DARPP-32 and PPI-1 are thus bifunctional signal transduction elements which modulate PKA signaling in response to their phosphorylation by Cdk5. D1 and D2 dopamine receptors found on the GABAergic dopaminoceptive medium spiny neurons of the striatum regulate motor behavioral functions by initiating the mutual and antagonistic actions of Cdk5 and PKA through balancing of kinase and phosphatase activities. ${ }^{71,72}$ In the neo-striatum, activation of metabotropic glutamatergic receptors increases Cdk5 and casein kinase-1 activity, resulting in the phosphorylation of DARPP-32 at Thr 75 and Ser 137 , respectively. ${ }^{72}$ Kinase inhibitor studies on neostriatal slices indicate that casein kinase-1 may function upstream of Cdk5. ${ }^{72,73}$

PKA is not the only kinase whose activity is modulated by Cdk5. Indeed, Cdk5 inhibits JNK-3 by phosphorylation on Thr 131 and prevents neuronal apoptosis. ${ }^{74}$ Moreover, Cdk5 can phosphorylate MAPK/Erk kinase-1 (MEK1) resulting in decreased extracellular regulated kinase (Erk) activity. ${ }^{75} \mathrm{~A}$ version of MEK1 mutated at Thr286 is unresponsive to Cdk5, suggesting that this residue is a Cdk5 regulatory phosphorylation site. ${ }^{75}$ Conversely, the MAPK pathway involving MEK1 and Erk also controls Cdk5 activity. Indeed, recent data suggest that an Erk-dependent induction of the transcription factor NGFI-A and its binding to the Egr (early growth response) sequence on the p35 promoter may contribute to upregulation of p35 expression following exposure to NGF. ${ }^{76}$ The binding of Sp transcription factors to the GC-box of the p35 promoter likely acts in synergy with NGFI-A binding to increase neuronal expression of $\mathrm{p} 35 .^{77}$

Induction of $\mathrm{p} 35 / \mathrm{Cdk} 5$ by the transcription factor DeltaFosB has recently been shown to be a key event regulating nerve terminal events induced by chronic administration of cocaine, which inhibits the re-uptake of dopamine originating from the substantia nigra $(\mathrm{Sn}){ }^{71,72}$ Inhibition of Cdk5 in the Sn following chronic exposure to cocaine potentiates the cocaine-induced locomotor behavioral response, thereby providing compelling evidence that Cdk5 plays important roles in motor functions, behavior and the effects induced by cocaine. ${ }^{71,72}$ Interestingly, the latter cocaine-induced response is accompanied by a remodeling of dendritic spines. This effect can be abolished by injection of Cdk5 inhibitors into the striatum, indicating that the cytoskeleton participates in this process (Greengard and colleagues, 31st Annual Meeting in Neurosciences, San Diego, 2001). Other behavioral abnormalities such as reduced aggressiveness in males and nurturing deficits in females are seen in p35 null mice. ${ }^{49}$ P35/Cdk5 is also required for associative learning. ${ }^{78}$

The role of Cdk5 in neuronal adaptive changes, plasticity and neurotransmission is not limited to its effects on the neuronal cytoskeleton. Cdk5 also controls presynaptic function by phosphorylating Munc18, amphysin and synapsin I. ${ }^{1}$ A role for p35/Cdk5 in synaptic transmission is further indicated by the observed susceptibility to seizures and lowered threshold for lethal seizure activity in p35-null mice and by the reported involvement of the kinase in downregulating $P / Q$-type voltage-dependent calcium channel activity. ${ }^{49,79}$ Phosphorylation of the regulatory subunit of retinal cGMP phosphodiesterase II by Cdk5 suggests a role for the kinase in modulating Gcoupled protein receptors during retinal cell neurotransmission. ${ }^{80}$ Cdk5 also regulates neurotransmission and longterm potentiation by phosphorylating the NR2A subunit of NMDA receptors at Ser1232. ${ }^{81}$ For a summary of pathways involving Cdk5, see Figure 3.

\section{Cdk5 in neurodegeneration}

The involvement of Cdk5 in neurodegeneration has been suggested by reports of Cdk5 expression in cells undergoing apoptosis and by the presence of the kinase in neurofibrillary tangles. The latter consist of paired helical filaments (PHF) made up of hyperphosphorylated tau and hyperphosphorylated NFs, and are found in $A D$ and Frontal Temporal 


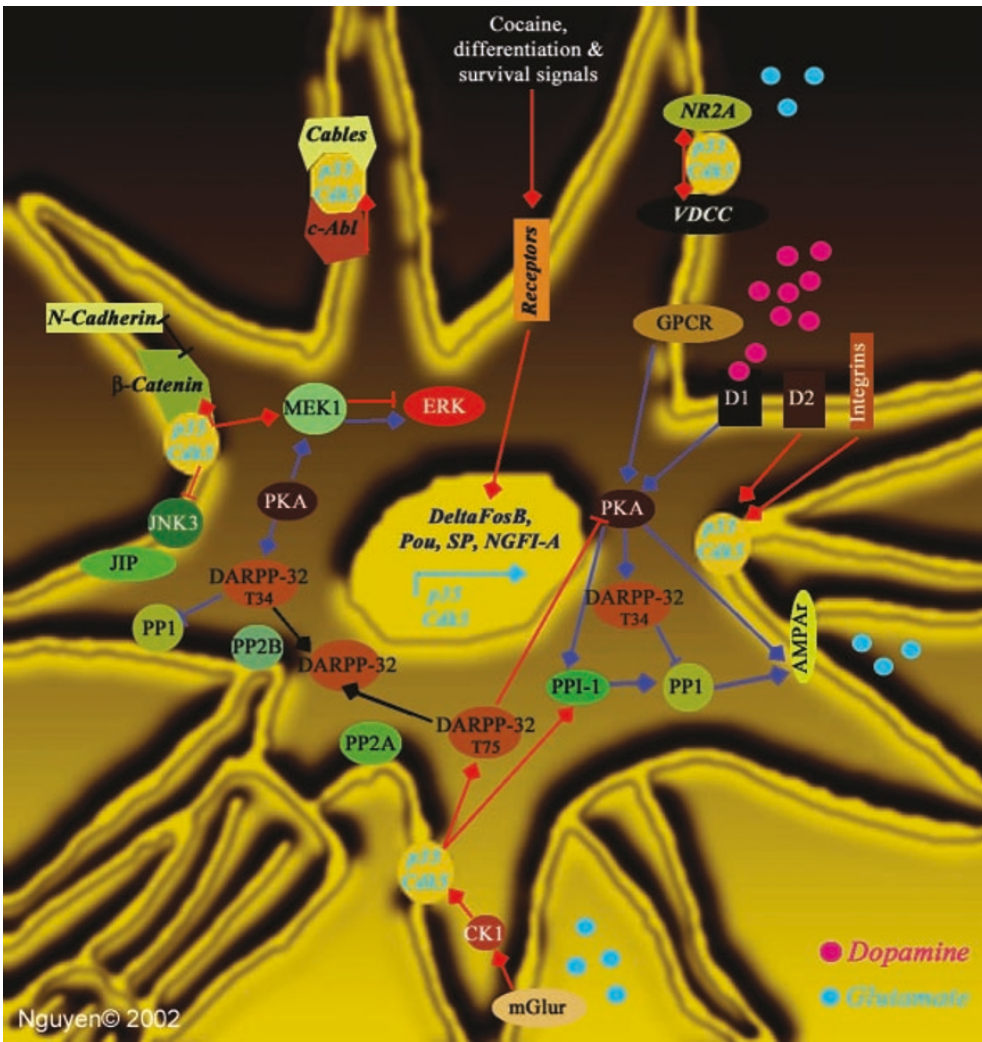

Figure 3 Signaling pathways controlled by Cdk5 in healthy neurons. Cdk5 is activated by c-Abl during neurite outgrowth via phosphorylation of Tyr 15 . Then, in association with p35, the kinase orchestrates multiple neuronal functions including the migration of neurons. This process relies on the dynamics of cell adhesion and actin-based motility. While phosphorylation of $\beta$-catenin by Cdk5 modulates its interactions with Cadherins, Cdk5 can also activate in a Rac-dependent manner PAK1, a kinase intimately to the actin cytoskeleton (not illustrated). Cdk5 also controls neurotransmission by phosphorylation of VDCC and the NR2A subunit of NMDA receptors. Activation of $\mathrm{p} 35 / \mathrm{Cdk5}$ can occur following stimulation of metabotropic glutamate receptors or integrins receptors. In dopaminoceptive neurons of the neostriatum, effects mediated by Cdk5 can be antagonized by the activation of PKA through the D1 receptors. DARPP32 and PPI1 are the main targets for Cdk5 and PKA. Phosphorylation of DARPP32 at Thr 75 by Cdk5 makes it a potent inhibitor of PKA whereas phosphorylation of DARPP32 at Thr 34 by PKA transforms DARPP32 into a potent inhibitor of PP1. In addition, activation of Cdk5 and subsequent phosphorylation of DARPP-32 by Cdk5 at Thr-75 is stimulated by D2 receptor activation. Moreover, phosphorylation of PPI-1 at Ser 67 by Cdk5 lowers the affinity of PKA for PPI-1 and thereby, modulates the balance between PP1 and PKA effects, notably at the level of AMPA receptors. Finally, p35/Cdk5 is able to phosphorylate MEK1 and JNK-3 and thus, negatively regulate the activity of JNK-3 and ERK. Therefore, the activity of Cdk5 is closely linked to the activity of other proline-directed serine/threonine kinases

Dementia-17 (FTD). ${ }^{82,83}$ The abnormal localization of Cdk5 is also found in canine motor neuron disease, Parkinson's disease as well as amyotrophic lateral sclerosis (ALS). ${ }^{84-86}$ The recent discovery that the truncated co-activators, p25 and p29, render Cdk5 neurotoxic and that p25 levels are elevated in $A D$ brains and in a mouse model of amyotrophic lateral sclerosis (ALS) supports the notion that rigorous regulation of Cdk5 is crucial for neuronal survival. ${ }^{1,46,87}$

\section{Generation of p25/p29}

The cdk5 co-activators p35 and p39 contain several Cdk5 phosphorylation consensus sites and a short proline-rich region in the $\mathrm{N}$-terminal third of the protein, which corresponds to the cleavage site for generating p25 and p29. ${ }^{46,88}$ As detailed in a recent review by Dhavan and Tsai (2002), the production of p25 and p29 in neurons correlates with exposure to agents that disrupt calcium homeostasis and is likely to involve calpain. ${ }^{47,89}$ P25 and p29, with half-lives of $1-2 \mathrm{~h}$, are much more stable than p35 and p39, which have half-lives of $20-30 \mathrm{~min}$, and their ability to associate with Cdk5 leads to sustained activation of the kinase. ${ }^{46,47}$ In contrast to p35 and p39, p25 and p29 lack the myristoylation sequence for membrane targeting and are therefore not associated with the plasma membrane $e^{46,47}$ (see Figure 4). Consequently, p25 and p29 remove Cdk5 from its normal compartments with p25/Cdk5 being located mainly in the cell body and nucleus and p29/Cdk5 in the cell soma and proximal neurites. ${ }^{46,47}$ Seldom are the two complexes seen in distal neuritis and growth cones. The altered distribution of Cdk5 impacts on the selection of substrates for phosphorylation and on the viability of neurons (see Figure 4).

The potential for conversion of p35 to p25 highlights the importance of factors affecting the stability of p35. Phosphorylation of p35 by Cdk5 reduces its stability, leading to its degradation by the proteasome system. ${ }^{88}$ Proteasome inhibition may thus keep p35 levels high. When p35 is not phosphorylated by Cdk5, it can be converted to p25 by calpain. ${ }^{46,88}$ Proteasome blockade, as reported to occur in neurodegenerative disorders, may thus 


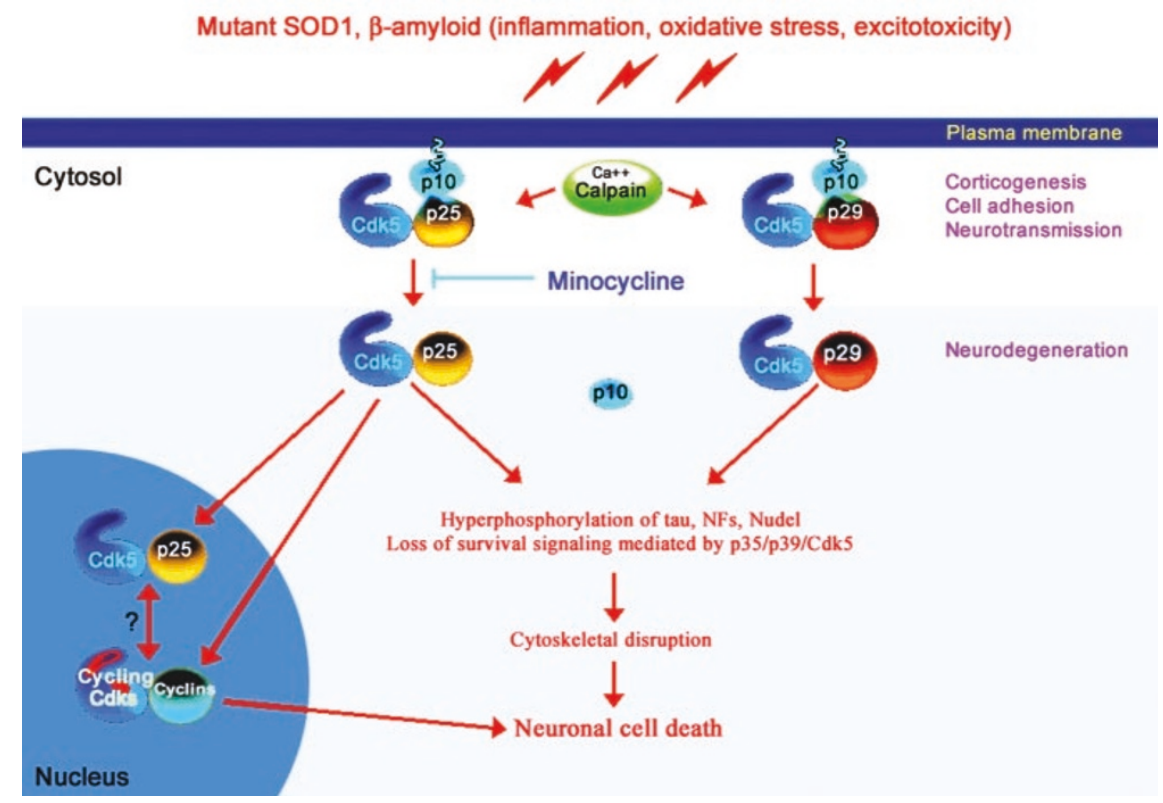

Figure 4 A model for neurological disorders involving Cdks. Cdk5 and cycling Cdks are central downstream effectors in neuronal apoptosis and neurodegeneration. Cdk5 is deregulated by p25 and p29, two calpain-truncated products. Calpain can be activated by inflammation, oxidative stress and excitotoxicity that result from genetic mutations (mutant SOD1) or altered metabolism ( $\beta$-amyloid). $\mathrm{P} 25 / \mathrm{Cdk} 5$ and p29/Cdk5 might aberrantly phosphorylate neuronal substrates including the microtubule-associated protein tau, Nudel and neurofilament proteins. Deregulation of Cdk5 might promote the induction and the activation of cell cycle Cdks in nucleus of injured neurons. It remains unknown whether p25/Cdk5 directly induces the transcription and activation of cycling Cdks. Alternatively, a cell cycle signaling in neurons might induce transcription of pro-apoptotic proteins as well as proteins involved in the cleavage of p35 into p25. The anti-apoptotic/anti-inflammatory compound minocycline indirectly attenuates Cdk5 deregulation and thereby, might inhibit the upregulation and mislocalization of cell cycle Cdks. Alternatively, conversion of p35 into p25 may result in loss of p35/Cdk5 complex, a major regulator of neuronal survival and maintenance. This may also contribute to neurodegeneration

make more p35 available for cleavage by calpain and thereby favor production of p25. ${ }^{90}$

\section{Neurotoxicity of p25 in Alzheimer's disease and Amyotrophic Lateral Sclerosis}

Studies have reported the accumulation of $\mathrm{p} 25 / \mathrm{Cdk} 5$ in neurons of $A D$ patients where it co-localizes with neurofibrillary tangles (NFT). ${ }^{46}$ Expression of p25/Cdk5 in cultured cortical neurons induced hyperphosphorylation of tau, neurite retraction, cytoskeletal abnormalities and apoptosis. $^{46}$ The involvement of p25 in neurodegeneration is further supported by a study showing that overexpression of p25 in the CNS of transgenic mice caused hyperphosphorylation of tau and NFs, cytoskeletal disruption and behavioural deficits reminiscent of AD. ${ }^{91}$ Moreover, transgenic mice that overexpress p25 under the PDGF promotor develop a motor neuron disease and paralysis reminiscent of ALS. ${ }^{92}$ In contrast, there is no evidence of hyperphosphorylated tau in triply transgenic p35/Cdk5/tau mice despite the elevated Cdk5 activity, and tau as well as NF phosphorylation are not altered in p35/p39 double knockout mice. ${ }^{44,93}$ All of these results support a noxious role for p25/ Cdk5 but not for p35/Cdk5 in neurodegeneration.

Another pathological hallmark of $A D$ is the presence of extracellular deposits of amyloid plaques composed of fibrillogenic amyloid $\beta(\mathrm{A} \beta)$ peptides. Treatment of cultured cortical neurons with $\mathrm{A} \beta$ peptide causes activation of calpain, production of p25, hyperphosphorylation of tau and ultimately, cell death. ${ }^{46,89}$ Inhibition of Cdk5 can partially prevent the neuronal apoptosis indicating that p25/Cdk5 is a player in A $\beta$-induced neurotoxicity. ${ }^{46,89,94}$ Although phosphorylation of JNK-3 by Cdk5 prevents neuronal apoptosis, JNK activation also appears to contribute to $A \beta$ toxicity independently of $\mathrm{Cdk} 5 .^{74,95}$

Increases in both the p25/p35 ratio and Cdk5 activity are also seen in the spinal cord of transgenic mice expressing a mutant form of superoxide dismutase (SOD) 1 linked to familial ALS (SOD1 ${ }^{\mathrm{G} 37 \mathrm{R}}$ ) (for a review on ALS, see ${ }^{96}$ ). Such p25-dependent deregulation of Cdk5 is associated with hyperphosphorylation of cytoskeletal NF and tau proteins at Cdk5 sites known to be hyperphosphorylated in AD. ${ }^{87}$ p25/ Cdk5 co-localizes with phosphorylated NF-H in cell bodies of motor neurons in (SOD1 ${ }^{\mathrm{G} 37 \mathrm{R}}$ mice and NF-H can be coimmunoprecipitated with $\mathrm{Cdk} 5 .^{87}$ The direct correlation between the presence of perikaryal accumulations of NF proteins in mutant SOD1 mice and lifespan extension in these mice, as well as the reduced phosphorylation of tau, supports the notion that Cdk5 participates in ALS pathogenesis. The perikaryal NF accumulations likely confer protection in SOD1G37R mice by acting as a phosphorylation sink for deregulated Cdk5 activity, thereby reducing the aberrant hyperphosphorylation of other cellular substrates $^{87}$ (see Figure 6).

New evidence for the involvement of Cdk5 in ALS pathogenesis is provided by a recent study reporting that 
treatment of mutant SOD1 mice with minocycline markedly abolishes the abnormal Cdk5 immunoreactivities in the nucleus, cell body and dendrites of motor neurons. ${ }^{97}$ The protective effect is partially due to alleviation of the mitogenic action of p38 MAPK on activated microglia and on caspases activation. Cdk5 deregulation thus paralleled the inflammatory process leading to motor neuron degeneration in mutant SOD1 mice. Then, deregulation of both cell cycle Cdks and Cdk5 may be linked to inflammation.

As with p25, p29 can also effect a sustained activation of Cdk5, suggesting that it may also play a role in neurodegeneration. As mentioned above, p35 and p39 are expressed in distinct overlapping populations of neurons and neuronal compartments. For example, p39 is enriched in motor neurons of the spinal cord. ${ }^{52}$ However, it is not known whether p29 contributes to the deregulation of Cdk5 associated with neurodegeneration in mutant SOD1 mice as well as in other neurological disorders associated with loss of spinal motor neurons.

\section{Putative Cdk5 targets in neurodegeneration}

A rigorous control of Cdk5 activity is essential for the maintenance and survival of neurons. The loss of Cdk5 or sustained association of the kinase with p25/p29 can trigger aberrant phosphorylation of substrates such as tau protein, which is noxious for neurons (for a summary, see Figure 4). Others substrates are potentially targets for p25/Cdk5 in neurodegeneration and ALS.

Nudel, a dynein interacting protein involved in the control of axonal transport, is a good substrate for p25/Cdk5. ${ }^{64}$ Lis1 and Nudel possess a coiled-coil domain and their functions could be intimately linked to the transport of the coiled-coil neuronal intermediate filaments (peripherin, alpha-internexin and NF triplets) by dyneins and kinesins, essential component of transport in motor neurons. Furthermore, the dynactin complex linked to dynein has been shown to bind at least one intermediate filament. ${ }^{98,99}$ The hyperphosphorylation of Nudel by p25/Cdk5 may destabilize Lis1/Nudel interactions and affects axonal transport mediated by dynein. Accumulations of neuronal intermediate filaments and dynein in axons, dendrites and cell bodies of degenerating neurons support the intriguing possibility (Nguyen, Smith, Julien and Tsai, unpublished observations). Concomitantly, a cleavage of p35 into p25 might result in a loss of p35/Cdk5. Thus, alterations in axonal transport might be caused by a loss of p35/Cdk5. Furthermore, since p35/cdk5 is crucial for neurotransmis-

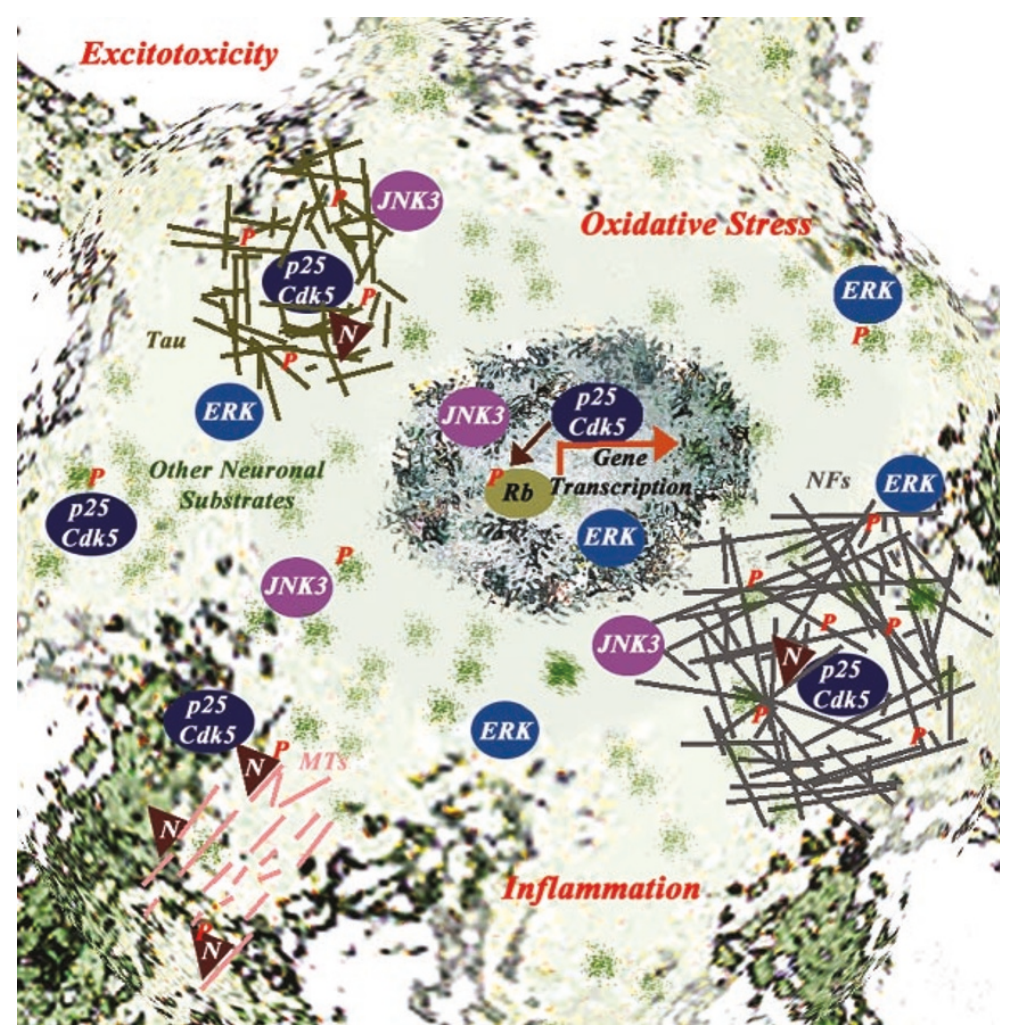

Figure 5 Deregulation of Cdk5: A general dysregulation of kinases? P35/Cdk5 has been shown to phosphorylate MEK1 and JNK-3 and thereby, negatively regulate the activity of JNK and ERK. Furthermore, p35/Cdk5 is able to antagonize the effects of PKA. Conversion of p35 into p25 simultaneously results in a loss of p35/Cdk5 complex and thereby, might lead to uncontrolled activity of JNK-3, ERK and PKA. This might lead to unbalance in signal transduction pathways controlled by these kinases. As a result, nudel, tau, NF proteins and other neuronal substrates including nuclear proteins are likely targets for JNK-3, ERK, and PKA. Potential alterations of gene transcription programs by p25/Cdk5 through Rb phosphorylation might receive the synergitic contribution of deregulated ERK and JNK3. Thus, the abnormal phosphorylation observed in neurodegenerative models where Cdk5 is deregulated might be caused by the synergistic contribution of different kinases 
sion, motor functions and neuronal survival, the loss of the complex might lead to electrophysiological defects and uncontrolled activation of ERK, JNK and PKA pathways. Thus, aberrant phosphorylation triggered by p25/Cdk5 is likely to be parallel to the abnormal phosphorylation of substrates mediated by deregulated ERK, JNK and PKA (see Figure 5).

Although $\mathrm{Bcl}-2$ phosphorylation plays a dual role in the regulation of apoptosis, inactivation of $\mathrm{Bcl}-2$ through phosphorylation by p25/Cdk5 leads to the disruption of mitochondrial homeostasis and apoptosis, reported in many neurodegenerative disorders (Tsai and colleagues, 30th Annual Meeting in Neurosciences, New Orleans, 2000). On a different but related front, p35/Cdk5 complex has been shown to phosphorylate $\beta$-catenin and modulate $\beta$-catenin/ presenilin-1 interactions. ${ }^{100}$ This interaction seems to be disrupted in Alzheimer's disease (AD). ${ }^{101}$ Conversion of p35/Cdk5 complex into p25/Cdk5 complex may then alter the dynamics of binding of $\beta$-catenin to presenilin-1 and consequently affects the stability of $\beta$-catenin. Indeed, a strong degradation of $\beta$-catenin has been reported in Alzheimer's patients. ${ }^{101}$ Such destabilization of $\beta$-catenin by mutant Presinilin in neuronal cells can trigger apoptosis by affecting transcription of survival genes. ${ }^{101}$ Alternatively, the findings of p25/Cdk5 in the nucleus of degenerating neurons support the idea that deregulated Cdk5 can alter transcription programs during neuronal cell death. A largescale proteomics approach on Cdk5 substrates will be invaluable for the deep understanding of neurodegeneration.

\section{A link between deregulation of Cdk5 and cell cycle activation in neurodegeneration}

In dividing cells, part of gene transcription programs is mediated by classical Cdks. In neurons, a fine interplay exists between the expression of Cdk5, p35/p39, essential for the maintenance of the differentiated state, and the silencing of cell cycle proteins such as Cdc2. Indeed, during development, the expression of Cdk5 is inversely proportional to the expression and activity of cdc2 (see above and Figure 1).

SP transcription factors (SP1, SP3 and SP4) that bind GC-box on TATA-less promoters have been shown to control both cell cycle and differentiation processes. SP1 has been implicated in the control of cell-cycle-regulated genes such as thymidine kinase and may be regulated by members of the retinoblastoma family. ${ }^{102}$ In contrast, SP4 is mainly found in the CNS suggesting an important role for this factor in neuronal expression. ${ }^{102}$ Interestingly, during differentiation, expression of p35 is regulated by variations in ratio and levels of SP transcription factors whose, consequently control Cdk5 activity. ${ }^{77}$ Alterations in expres-

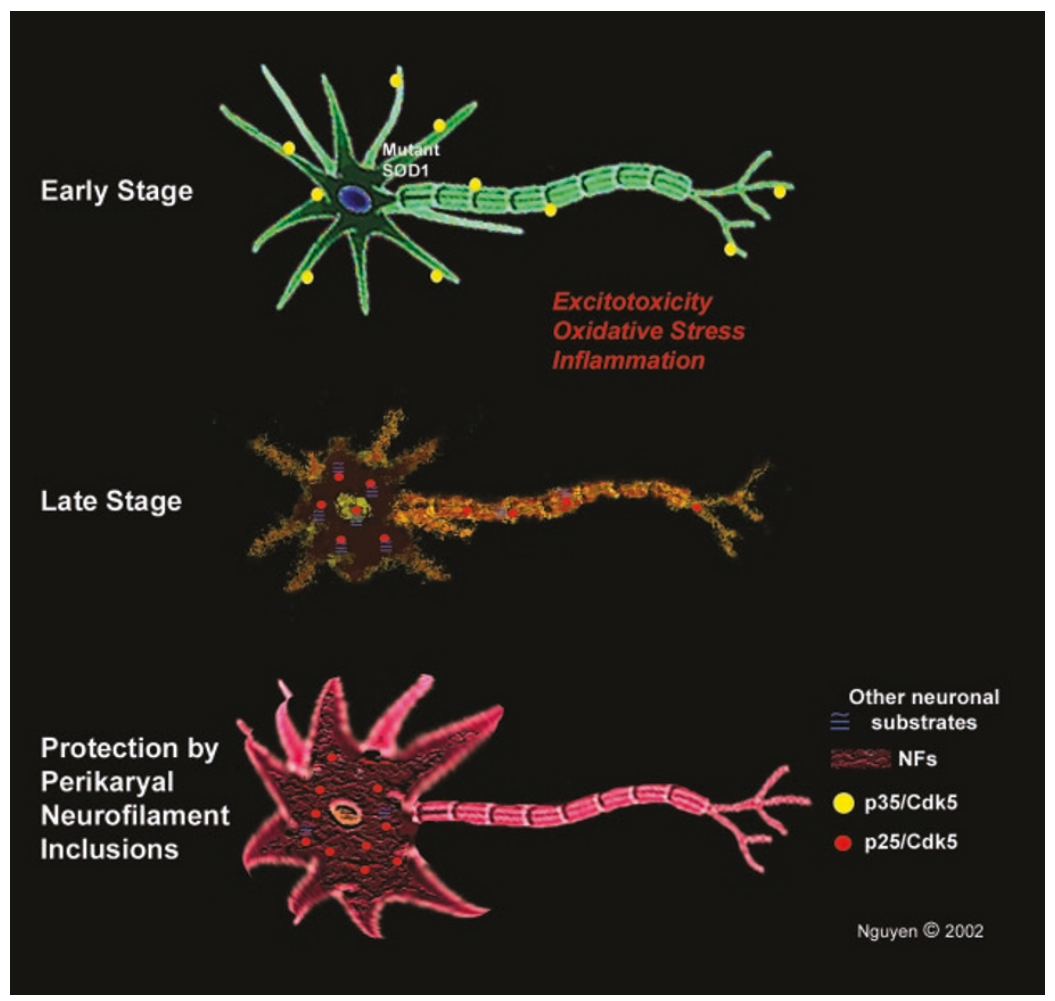

Figure 6 Perikaryal NF accumulations: A phosphorylation sink for deregulated Cdk5 in a mouse model of ALS. At early stages of the mutant SOD1-mediated disease, p35 is the main Cdk5 co-activator in motor neurons and the p35/Cdk5 complex is associated with peripheral membranes in those nerve cells. During aging and progression of disease, mutant SOD1 induce inflammation, oxidative stress and excitotoxicity. These pathogenic events promote the conversion of p35 into p25. As a result, p25/Cdk5 trigger aberrant phosphorylation of nuclear and cytosolic substrates such as tau and NF proteins causing neurite retraction and degeneration. Accumulations of NFs in perykarya may protect motor neurons by alleviating the detrimental phosphorylation of other neuronal substrates 
sion of neuronal genes by members of this transcription family can have a direct impact on the dedifferentiation of neurons and thereby, induce cell cycle proteins and neuronal death.

The interplay between expression of Cdk5, p35 and p39 and regulation of cell cycle proteins such as Cdk1 that occurs during neuronal differentiation is disrupted in neurological disorders (see Figure 1). Indeed, deregulation of Cdk5 in motor neurons of SOD1 ${ }^{\mathrm{G} 37 \mathrm{R}}$ mice and forebain neurons of $A D$ patients is associated with the upregulation of Cdk4 levels/activity and of cell cycle proteins (see above). Evidence that p25 mislocalizes Cdk5 to the nucleus together with data showing an association of Cdk5 with transcription factors and transcription factors-associated proteins such as $\mathrm{c}-\mathrm{Abl}, \mathrm{Rb}$ and MEF2, cyclin protein, suggests that Cdk5 may participate in transcription, including those of cell cycle proteins in degenerating neurons. The upregulation of nuclear Cdk4 in motor neurons of SOD1 ${ }^{\mathrm{G} 37 \mathrm{R}}$ mice is alleviated by a transgene encoding human NF-H, which is a phosphorylation sink for deregulated Cdk5, resulting in alleviation of the disease (Nguyen et al., unpublished observations). These results suggest that the deregulation of Cdk5 lies upstream of Cdk4 activation in ALS and, perhaps, in other neurodegenerative pathways.

\section{Concluding remarks}

Although Cdk5 and cycling Cdks do not function concomitantly in the healthy adult CNS, there are numerous reports supporting their active co-participation in neurodegeneration. Cell cycle Cdks likely direct neurons to their demise by inducing transcription of cell cycle-related and pro-apoptotic genes whereas p25/Cdk5 promotes neurodegeneration through mechanisms that include aberrant phosphorylation of cytoskeletal proteins such as NFs, tau, and Nudel. It is also possible that the loss of p35/Cdk5 that accompanies the conversion of p35 to p25 may have a significant impact on neuronal processes involving p35/Cdk5. The possibility that deregulation of Cdk5 might also trigger cell cycle signaling in neurons suggests a synergistic action of Cdk family members in neurodegeneration. In animal models of ALS and in AD, Cdk5 is found in the nucleus. Small oscillations in $\mathrm{Ca} 2+$ concentration are sufficient to promote conversion of p35 to p25, thus causing misclocalization of Cdk5. This may result in direct regulation of cell cycle proteins by nuclear p25/Cdk5 in neurons and ensuing cell death.

The evident interaction between Cdk5 and cell cycle proteins must, however, be considered in the appropriate context because some studies point to the localization of p35/Cdk5 in the nucleus ${ }^{103,104}$ and the nuclear SET protein was shown to bind p35 but not p25 and thus modulate nuclear p35/Cdk5 activity. ${ }^{105}$ Improved resolution of transcription complexes comprising elements of the dormant cell cycle machinery (Cdk, cyclin, $\mathrm{CKI}$ ) and those involving Cdk5 and its co-activators (p25, p35, p29, p39) both inside the neuronal nucleus and in the cytoplasm should contribute to better define the interface between cycling and non-cycling members of this important family of kinases.

\section{Acknowledgements}

Due to lack of space, we were unable to cite all papers relevant to the topic. We apologize for this inconvenience. This work is supported by the Canadian Institutes of Health Research (CIHR) (to WE Mushynski and J-P Julien), the ALS Society of Canada, the Neuromuscular Funds, the National Institutes of Health (USA) and the Center for Research on ALS at Johns Hopkins University (to J-P Julien). MD Nguyen was a recipient of a KM Hunter-CIHR Ph.D. Scholarship and is currently supported by a Human Frontier Science Program Long-Term Fellowship. WE Mushynski is a CIHR Scientist. J-P Julien holds a CIHR Senior Investigator Award.

\section{References}

1. Dhavan R and Tsai LH (2001) A decade of CDK5. Nat. Rev. Mol. Cell Biol. 2: $749-759$

2. Tannoch VJ, Hinds PW and Tsai LH (2000) Cell cycle control. Adv. Exp. Med. Biol. 465: $127-140$

3. Morgan DO (1997) Cyclin-dependent kinases: engines, clocks, and microprocessors. Annu. Rev. Cell Dev. Biol. 13: 261-291

4. Okano HJ, Pfaff DW and Gibbs RB (1993) RB and Cdc2 expression in brain: correlations with $3 \mathrm{H}$-thymidine incorporation and neurogenesis. J. Neurosci. 13: $2930-2938$

5. Xiong W, Pestell R and Rosner MR (1997) Role of cyclins in neuronal differentiation of immortalized hippocampal cells. Mol. Cell Biol. 17: 65856597

6. Pavletich NP (1999) Mechanisms of cyclin-dependent kinase regulation: structures of Cdks, their cyclin activators, and Cip and INK4 inhibitors. J. Mol. Biol. 287: 821-828

7. Mueller PR, Coleman TR and Dunphy WG (1995) Cell cycle regulation of a Xenopus Wee1-like kinase. Mol. Biol. Cell 6: 119-134

8. Mueller PR, Coleman TR, Kumagai A and Dunphy WG (1995) Myt1: a membrane-associated inhibitory kinase that phosphorylates $\mathrm{Cdc} 2$ on both threonine-14 and tyrosine-15. Science 270: 86-90

9. GuY, Rosenblatt J and Morgan DO (1992) Cell cycle regulation of CDK2 activity by phosphorylation of Thr160 and Tyr15. EMBO J. 11: 3995-4005

10. Kumagai A and Dunphy WG (1995) Control of the Cdc2/cyclin B complex in Xenopus egg extracts arrested at a G2/M checkpoint with DNA synthesis inhibitors. Mol. Biol. Cell 6: 199-213

11. Dunphy WG and Kumagai $A$ (1991) The cdc25 protein contains an intrinsic phosphatase activity. Cell 67: 189-196

12. Zukerberg LR, Patrick GN, Nikolic M, Humbert S, Wu CL, LanierLM, Gertler FB, Vidal M, Van Etten RA and Tsai LH (2000) Cables links Cdk5 and c-Abl and facilitates Cdk5 tyrosine phosphorylation, kinase upregulation, and neurite outgrowth. Neuron 26: 633-646

13. Matsuura I and Wang JH (1996) Demonstration of cyclin-dependent kinase inhibitory serine/threonine kinase in bovine thymus. J. Biol. Chem. 271:54435450

14. Sharma P, Sharma M, Amin ND, Albers RW and Pant HC (1999) Regulation of cyclin-dependent kinase 5 catalytic activity by phosphorylation. Proc. Natl. Acad. Sci. USA 96: 11156-11160

15. Tarricone C, Dhavan R, Peng J, Areces LB, Tsai LH and Musacchio A (2001) Structure and regulation of the CDK5-p25(nck5a) complex. Mol. Cell. 8: 657669

16. Lee MH, Nikolic M, Baptista CA, Lai E, Tsai LH and Massague J (1996) The brain-specific activator p35 allows Cdk5 to escape inhibition by p27Kip1 in neurons. Proc. Natl. Acad. Sci. USA 93: 3259-3263

17. Ching YP, Pang AS, Lam WH, Qi RZ and Wang JH (2002) Identification of a neuronal Cdk5 activator-binding protein as Cdk5 inhibitor. J. Biol. Chem. 277: $15237-15240$

18. Songyang Z, Lu KP, Kwon YT, Tsai LH, Filhol O, Cochet C, Brickey DA, Soderling TR, Bartleson C, Graves DJ, DeMaggio AJ, Hoekstra MF, Blenis J, Hunter T and Cantley LC (1996) A structural basis for substrate specificities of protein Ser/Thr kinases: primary sequence preference of casein kinases I and II, NIMA, phosphorylase kinase, calmodulin-dependent kinase II, CDK5, and Erk1. Mol. Cell. Biol. 16: 6486-6493 
19. Julien JP and Mushynski WE (1998) Neurofilaments in health and disease. Prog. Nucleic. Acid. Res. Mol. Biol. 61: 1-23

20. Endicott JA and Noble ME (1998) Structural principles in cell-cycle control: beyond the CDKs. Structure 6: 535-541

21. Saha P, Eichbaum Q, Silberman ED, MayerBJ and Dutta A(1997)p21CIP1 and Cdc25A: competition between an inhibitor and an activator of cyclin-dependent kinases. Mol. Cell. Biol. 17: 4338-4345

22. WohlschlegelJA, DwyerBT, Takeda DY and Dutta A (2001) Mutational analysis of the Cy motif from p21 reveals sequence degeneracy and specificity for different cyclin-dependent kinases. Mol. Cell. Biol. 21: 4868-4874

23. Tsai LH, Takahashi T, Caviness Jr VS and Harlow E (1993) Activity and expression pattern of cyclin-dependent kinase 5 in the embryonic mouse nervous system. Development 119: 1029-1040

24. Carey RG, Li B and DiCicco-Bloom E (2002) Pituitary adenylate cyclase activating polypeptide anti-mitogenic signaling in cerebral cortical progenitors is regulated by p57Kip2-dependent CDK2 activity. J. Neurosci. 22: 1583-1591

25. Legrier ME, Ducray A, Propper A and Kastner A (2001) Region-specific expression of cell cycle inhibitors in the adult brain. Neuroreport 12: $3127-$ 3131

26. Gill RM, Slack R, Kiess M and Hamel PA (1998) Regulation of expression and activity of distinct pRB, E2F, D-type cyclin, and CKI family members during terminal differentiation of P19 cells. Exp. Cell. Res. 244: 157-170

27. Berke JD, Sgambato V, Zhu PP, Lavoie B, Vincent M, Krause M and Hyman SE (2001) Dopamine and glutamate induce distinct striatal splice forms of Ania-6, an RNA polymerase II-associated cyclin. Neuron 32: 277-287

28. Lazzaro MA, AlbertPR and Julien JP (1997) A novel cdc2-related protein kinase expressed in the nervous system. J. Neurochem. 69: 348-364

29. Liu DX and Greene LA (2001) Neuronal apoptosis at the G1/S cell cycle checkpoint. Cell Tissue Res. 305: 217-228

30. Husseman JW, Nochlin D and Vincent I (2000) Mitotic activation: a convergent mechanism for a cohort of neurodegenerative diseases. Neurobiol. Aging 21: $815-828$

31. Park DS, Obeidat A, Giovanni A and Greene LA (2000) Cell cycle regulators in neuronal death evoked by excitotoxic stress: implications for neurodegeneration and its treatment. Neurobiol. Aging 21: 771-781

32. Osuga H, Osuga S, Wang F, Fetni R, Hogan MJ, Slack RS, Hakim AM, Ikeda JE and Park DS (2000) Cyclin-dependent kinases as a therapeutic target for stroke. Proc. Natl. Acad. Sci. USA 97: 10254-10259

33. Ino Hand Chiba T (2001) Cyclin-dependent kinase 4 and cyclin D1 are required for excitotoxin-induced neuronal cell death in vivo. J. Neurosci. 21:6086-6094

34. Giovanni A, Keramaris E, Morris EJ, Hou ST, O'Hare M, Dyson N, Robertson GS, Slack RS and Park DS (2000) E2F1 mediates death of B-amyloid-treated cortical neurons in a manner independent of p53 and dependent on Bax and caspase 3. J. Biol. Chem. 275: 11553-11560

35. Liu DX and Greene LA (2001) Regulation of neuronal survival and death by E2Fdependent gene repression and derepression. Neuron 32: 425-438

36. Jordan-Sciutto KL, Malaiyandi LM and Bowser R (2002) Altered distribution of cell cycle transcriptional regulators during Alzheimer disease. J. Neuropathol. Exp. Neurol. 61: 358-367

37. Nguyen MD, Julien JP and Rivest S (2002) Innate immunity: the missing link in neuroprotection and neurodegeneration? Nat. Rev. Neurosci. 3: 216-227

38. ZhuX, Rottkamp CA, Raina AK, Brewer GJ, Ghanbari HA, Boux Hand Smith MA (2000) Neuronal CDK7 in hippocampus is related to aging and Alzheimer disease. Neurobiol. Aging 21: 807-813

39. Vincent I, Bu B, Hudson K, Husseman J, Nochlin D and Jin L (2001) Constitutive Cdc25B tyrosine phosphatase activity in adult brain neurons with $\mathrm{M}$ phase-type alterations in Alzheimer's disease. Neuroscience 105: 639-650

40. Ding XL, Husseman J, Tomashevski A, Nochlin D, Jin LW and Vincent I (2000) The cell cycle Cdc25A tyrosine phosphatase is activated in degenerating postmitotic neurons in Alzheimer's disease. Am. J. Pathol. 157: 1983-1990

41. Vincent I, Jicha G, Rosado M and Dickson DW (1997) Aberrant expression of mitotic cdc2/cyclin B1 kinase in degenerating neurons of Alzheimer's disease brain. J. Neurosci. 17: 3588-3598

42. Yang $Y$, Geldmacher DS and Herrup K (2001) DNA replication precedes neuronal cell death in Alzheimer's disease. J. Neurosci. 21: 2661-2668

43. Tsai LH, Delalle I, Caviness Jr VS, Chae T and Harlow E (1994) p35 is a neuralspecific regulatory subunit of cyclin-dependent kinase 5. Nature 371:419-423

44. Ko J, Humbert S, Bronson RT, Takahashi S, Kulkarni AB, Li E and Tsai LH (2001) p35 and p39 are essential for cyclin-dependent kinase 5 function during neurodevelopment. J. Neurosci. 21:6758-6771
45. Tang D, Yeung J, Lee KY, Matsushita M, Matsui H, Tomizawa K, Hatase $\mathrm{O}$ and Wang JH (1995) An isoform of the neuronal cyclin-dependent kinase 5 (Cdk5) activator. J. Biol. Chem. 270: 26897-26903

46. Patrick GN, Zukerberg L, Nikolic M, de la Monte S, Dikkes P and Tsai LH (1999) Conversion of p35 to p25 deregulates Cdk5 activity and promotes neurodegeneration. Nature 402: 615-622

47. Patzke $\mathrm{H}$ and Tsai LH (2002) Calpain-mediated cleavage of the cyclindependent kinase 5 activator p39 to p29. J. Biol. Chem.

48. Kwon YT and Tsai LH (1998) A novel disruption of cortical development in p35(-/-) mice distinct from reeler. J. Comp. Neurol. 395: 510-522

49. Chae T, Kwon YT, Bronson R, Dikkes P, Li E and Tsai LH (1997) Mice lacking p35, a neuronal specific activator of Cdk5, display cortical lamination defects, seizures, and adult lethality. Neuron 18: 29-42

50. Delalle I, Bhide PG, Caviness Jr VS and Tsai LH (1997) Temporal and spatial patterns of expression of $\mathrm{p} 35$, a regulatory subunit of cyclin-dependent kinase 5, in the nervous system of the mouse. J. Neurocytol. 26: 283-296

51. Ino H, Ishizuka T, Chiba T and Tatibana M (1994) Expression of CDK5 (PSSALRE kinase), a neural cdc2-related protein kinase, in the mature and developing mouse central and peripheral nervous systems. Brain Res. 661: 196-206

52. Zheng M, Leung CL and Liem RK (1998) Region-specific expression of cyclindependent kinase 5 (cdk5) and its activators, p35 and p39, in the developing and adult rat central nervous system. J. Neurobiol. 35: 141-159

53. Cai XH, Tomizawa K, Tang D, Lu YF, Moriwaki A, Tokuda M, Nagahata S Hatase $O$ and Matsui $H$ (1997) Changes in the expression of novel Cdk5 activator messenger RNA (p39nck5ai mRNA) during rat brain development. Neurosci. Res. 28: 355-360

54. Humbert S, Dhavan R and Tsai L (2000) p39 activates cdk5 in neurons, and is associated with the actin cytoskeleton. J. Cell. Sci. 113 (Pt 6): 975-983

55. Nikolic M, Chou MM, Lu W, Mayer BJ and Tsai LH (1998) The p35/Cdk5 kinase is a neuron-specific Rac effector that inhibits Pak1 activity. Nature 395: $194-$ 198

56. RashidT, Banerjee M and Nikolic M (2001) Phosphorylation of Pak1 by the p35/ Cdk5 kinase affects neuronal morphology. J. Biol. Chem. 276: 49043-49052

57. Paglini G, Peris L, Diez-Guerra J, Quiroga S and Caceres A (2001) The Cdk5p35 kinase associates with the Golgi apparatus and regulates membrane traffic. EMBO Rep. 2: $1139-1144$

58. Ohshima T, Ward JM, Huh CG, Longenecker G, Veeranna, Pant HC, Brady RO, Martin LJ and Kulkarni AB (1996) Targeted disruption of the cyclin-dependent kinase 5 gene results in abnormal corticogenesis, neuronal pathology and perinatal death. Proc. Natl. Acad. Sci. USA 93: 11173-11178

59. Gilmore EC and Herrup K (2001) Neocortical cell migration: GABAergic neurons and cells in layers I and VI move in a cyclin-dependent kinase 5independent manner. J. Neurosci. 21: 9690-9700

60. Tanaka T, Veeranna, Ohshima T, Rajan P, Amin ND, Cho A, Sreenath T, Pant $\mathrm{HC}$, Brady RO and Kulkarni AB (2001) Neuronal cyclin-dependent kinase 5 activity is critical for survival. J. Neurosci. 21:550-558

61. Ohshima T, Gilmore EC, Longenecker G, Jacobowitz DM, Brady RO, Herrup K and Kulkarni $A B$ (1999) Migration defects of cdk5 $(-/-)$ neurons in the developing cerebellum is cell autonomous. J. Neurosci. 19: 6017-6026

62. Reiner O (2000) LIS1. let's interact sometimes (part 1). Neuron 28: 633-636

63. Smith DS, Niethammer M, Ayala R, Zhou Y, Gambello MJ, Wynshaw-Boris A and Tsai LH (2000) Regulation of cytoplasmic dynein behaviour and microtubule organization by mammalian Lis1. Nat. Cell Biol. 2: 767-775

64. Niethammer M, Smith DS, Ayala R, Peng J, Ko J, Lee MS, Morabito M and Tsai LH (2000) NUDEL is a novel Cdk5 substrate that associates with LIS1 and cytoplasmic dynein. Neuron 28: 697-711

65. McEvilly RJ, de Diaz MO, Schonemann MD, Hooshmand F and Rosenfeld MG (2002) Transcriptional regulation of cortical neuron migration by POU domain factors. Science 295: 1528-1532

66. Rice DS and Curran T (2001) Role of the reelin signaling pathway in central nervous system development. Annu. Rev. Neurosci. 24: 1005-1039

67. Ohshima T, Ogawa M, Veeranna, Hirasawa M, Longenecker G, IshiguroK, Pant HC, Brady RO, Kulkarni AB and Mikoshiba K (2001) Synergistic contributions of cyclin-dependant kinase 5/p35 and Reelin/Dab1 to the positioning of cortical neurons in the developing mouse brain. Proc. Natl. Acad. Sci. USA 98: $2764-$ 2769 
68. Keshvara L, Magdaleno S, Benhayon D and Curran T (2002) Cyclin-dependent kinase 5 phosphorylates disabled 1 independently of Reelin signaling. J. Neurosci. 22: 4869-4877

69. Kwon YT, Gupta A, Zhou Y, Nikolic M and Tsai LH (2000) Regulation of Ncadherin-mediated adhesion by the p35-Cdk5 kinase. Curr. Biol. 10: 363-372

70. Kwon YT, Tsai LH and Crandall JE (1999) Callosal axon guidance defects in p35(-/-) mice. J. Comp. Neurol. 415: 218-229

71. Gupta A and Tsai LH (2001) Neuroscience. A kinase to dampen the effects of cocaine? Science 292: 236-237

72. Greengard $P(2001)$ The neurobiology of slow synaptic transmission. Science 294: $1024-1030$

73. Liu F, Ma XH, Ule J, Bibb JA, Nishi A, DeMaggio AJ, Yan Z, Nairn AC and GreengardP (2001) Regulation of cyclin-dependent kinase 5 and casein kinase 1 by metabotropic glutamate receptors. Proc. Natl. Acad. Sci. USA 98: 1106211068

74. Li BS, Zhang L, Takahashi S, Ma W, Jaffe H, Kulkarni AB and Pant HC (2002) Cyclin-dependent kinase 5 prevents neuronal apoptosis by negative regulation of c-Jun N-terminal kinase 3. EMBO J. 21: 324-333

75. Sharma P, Veeranna, Sharma M, Amin ND, Sihag RK, Grant P, Ahn N, Kulkarni $A B$ and Pant $\mathrm{HC}$ (2002) Phosphorylation of MEK 1 by cdk5/p35 down-regulates the mitogen-activated protein kinase pathway. J. Biol. Chem. 277: 528-534

76. Harada T, Morooka T, Ogawa S and Nishida E (2001) ERK induces p35, a neuron-specific activator of Cdk5, through induction of Egr1. Nat. Cell. Biol. 3: 453-459

77. Ross S, Tienhaara A, Lee MS, Tsai LH and Gill G (2002) GC Box-binding Transcription Factors Control the Neuronal Specific Transcription of the Cyclindependent Kinase 5 Regulator p35. J. Biol. Chem. 277: 4455-4464

78. Fischer A, Sananbenesi F, Schrick C, Spiess J and Radulovic J (2002) Cyclindependent kinase 5 is required for associative learning. J. Neurosci. 22:37003707

79. Tomizawa K, Ohta J, Matsushita M, Moriwaki A, Li ST, Takei K and Matsui H (2002) Cdk5/p35 regulates neurotransmitter release through phosphorylation and downregulation of $\mathrm{P} / \mathrm{Q}$-type voltage-dependent calcium channel activity.J. Neurosci. 22: 2590-2597

80. Matsuura I, Bondarenko VA, Maeda T, Kachi S, Yamazaki M, Usukura J, Hayashi F and Yamazaki A (2000) Phosphorylation by cyclin-dependent protein kinase 5 of the regulatory subunit of retinal cGMP phosphodiesterase. I. Identification of the kinase and its role in the turnoff of phosphodiesterase in vitro. J. Biol. Chem. 275: 32950-32957

81. Li BS, Sun MK, Zhang L, Takahashi S, Ma W, Vinade L, Kulkarni AB, Brady RO and Pant HC (2001) Regulation of NMDA receptors by cyclin-dependent kinase-5. Proc. Natl. Acad. Sci. USA 98: 12742-12747

82. Yamaguchi $\mathrm{H}$, Ishiguro $\mathrm{K}$, Uchida T, Takashima A, Lemere $\mathrm{CA}$ and Imahori $\mathrm{K}$ (1996) Preferential labeling of Alzheimer neurofibrillary tangles with antisera for tau protein kinase (TPK) l/glycogen synthase kinase-3 beta and cyclindependent kinase 5, a component of TPK II. Acta Neuropathol (Berl) 92: 232241

83. Pei JJ, Grundke-lqbal I, Iqbal K, Bogdanovic N, Winblad B and Cowburn RF (1998) Accumulation of cyclin-dependent kinase 5 (cdk5) in neurons with early stages of Alzheimer's disease neurofibrillary degeneration. Brain Res. 797: 267-277

84. Bajaj NP, Al-Sarraj ST, Anderson V, Kibble M, Leigh N and Miller CC (1998) Cyclin-dependent kinase- 5 is associated with lipofuscin in motor neurones in amyotrophic lateral sclerosis. Neurosci. Lett. 245: 45-48

85. Nakamura S, Kawamoto Y, Nakano S, Akiguchi I and Kimura J (1997) p35nck5a and cyclin-dependent kinase 5 colocalize in Lewy bodies of brains with Parkinson's disease. Acta Neuropathol. (Berl) 94: 153-157

86. Green SL, Vulliet PR, Pinter MJ and Cork LC (1998) Alterations in cyclindependent protein kinase 5 (CDK5) protein levels, activity and immunocytochemistry in canine motor neuron disease. J. Neuropathol. Exp. Neurol. 57: $1070-1077$
87. Nguyen MD, Lariviere RC and Julien JP (2001) Deregulation of C dk5 in a mouse model of ALS: toxicity alleviated by perikaryal neurofilament inclusions. Neuron 30: $135-147$

88. Patrick GN, Zhou P, Kwon YT, Howley PM and Tsai LH (1998) p35, the neuronal-specific activator of cyclin-dependent kinase 5 (Cdk5) is degraded by the ubiquitin-proteasome pathway. J. Biol. Chem. 273: 24057-24064

89. Lee MS, Kwon YT, Li M, Peng J, Friedlander RM and Tsai LH (2000) Neurotoxicity induces cleavage of $p 35$ to $p 25$ by calpain. Nature 405: 360-364

90. Sherman MY and Goldberg AL (2001) Cellular defenses against unfolded proteins: a cell biologist thinks about neurodegenerative diseases. Neuron 29: $15-32$

91. Ahlijanian MK, Barrezueta NX, Williams RD, Jakowski A, Kowsz KP, McCarthy S, Coskran T, Carlo A, Seymour PA, Burkhardt JE, Nelson RB and McNeish JD (2000) Hyperphosphorylated tau and neurofilament and cytoskeletal disruptions in mice overexpressing human p25, an activator of cdk5. Proc. Natl. Acad. Sci. USA 97: 2910-2915

92. Bian F, Nath R, Sobocinski G, Booher RN, Lipinski WJ, Callahan MJ, Pack A, Wang KK and Walker LC (2002) Axonopathy, tau abnormalities, and dyskinesia, but no neurofibrillary tangles in p25-transgenic mice. J. Comp. Neurol. 446: 257-266

93. Van den Haute C, Spittaels K, Van Dorpe J, Lasrado R, Vandezande K, Laenen I, Geerts $\mathrm{H}$ and Van Leuven F (2001) Coexpression of human cdk5 and its activator p35 with human protein tau in neurons in brain of triple transgenic mice. Neurobiol. Dis. 8: 32-44

94. Alvarez A, Toro R, Caceres A and Maccioni RB (1999) Inhibition of tau phosphorylating protein kinase cdk5 prevents beta-amyloid-induced neuronal death. FEBS Lett. 459: 421-426

95. Wei W, Wang $X$ and Kusiak JW (2002) Signaling events in Amyloid beta peptide-induced neuronal death and IGF-I protection. J. Biol. Chem. 277: $17649-17656$

96. Julien JP (2001) Amyotrophic lateral sclerosis, unfolding the toxicity of the misfolded. Cell 104: 581-591

97. Kriz J, Nguyen MD and Julien JP (2002) Minocycline Slows Disease Progression in a Mouse Model of Amyotrophic Lateral Sclerosis. Neurobiol. Dis. in press

98. Shah JV, Flanagan LA, Janmey PA and Leterrier JF (2000) Bidirectional translocation of neurofilaments along microtubules mediated in part by dynein/ dynactin. Mol. Biol. Cell. 11: 3495-3508

99. Kreitzer G, Liao G and Gundersen GG (1999) Detyrosination of tubulin regulates the interaction of intermediate filaments with microtubules in vivo via a kinesin-dependent mechanism. Mol. Biol. Cell. 10: 1105-1118

100. Kesavapany S, Lau KF, McLoughlin DM, Brownlees J, Ackerley S, Leigh PN, Shaw CE and Miller CC (2001) p35/cdk5 binds and phosphorylates betacatenin and regulates beta-catenin/presenilin-1 interaction. Eur. J. Neurosci. 13: $241-247$

101. Zhang Z, Hartmann H, Do VM, Abramowski D, Sturchler-Pierrat C, Staufenbiel M, Sommer B, van de Wetering M, Clevers H, Saftig P, De Strooper B, He X and Yankner BA (1998) Destabilization of beta-catenin by mutations in presenilin-1 potentiates neuronal apoptosis. Nature 395: 698-702

102. Suske G (1999) The Sp-family of transcription factors. Gene 238: 291-300

103. Ino $\mathrm{H}$ and Chiba $\mathrm{T}$ (1996) Intracellular localization of cyclin-dependent kinase 5 (CDK5) in mouse neuron: CDK5 is located in both nucleus and cytoplasm. Brain Res. 732: $179-185$

104. Philpott A, Porro EB, Kirschner MW and Tsai LH (1997) The role of cyclindependent kinase 5 and a novel regulatory subunit in regulating muscle differentiation and patterning. Genes Dev. 11: 1409-1421

105. Qu D, Li Q, Lim HY, Cheung NS, Li R, Wang JH and Qi RZ (2001) Protein SET binds neuronal $\mathrm{Cdk5}$ activator p35nck $\mathrm{a}$ and modulates $\mathrm{Cdk5} / \mathrm{p} 35 \mathrm{nck} \mathrm{k}^{5} \mathrm{a}$ activity. J. Biol. Chem. 277: 7329-7332 